\title{
Effect of Magnesium Oxide Nanoparticles and Banana Peels on the Gel Strength of Water Base Mud
}

\author{
Sunday Agbons Igbinere ${ }^{1 *}$ Ikponmwosa Ohenhen ${ }^{2}$ \\ 1. Department of Petroleum Engineering, University of Benin, PMB 1154, Benin City, Nigeria \\ 2. Department of Petroleum Engineering, University of Benin, PMB 1154, Benin City, Nigeria
}

\begin{abstract}
Gel strength is a very important drilling fluid property as it represents the ability of the drilling fluid to suspend cuttings. Failure to use a mud of right gel strength could result in stuck pipe due to poor cutting suspension and formation damage due to high circulation pressure to break the gel. Nanoparticles (NPs) are considered as very good candidates for smart drilling fluid formation adequate in getting the desired gel strength because it can be used to achieve fluids with tailor made rheological properties, due to their unique physio-chemical properties. This work experimentally looked at determining the effect of magnesium oxides nanoparticles and banana peel on the gel strength of water base mud. Laboratory preparations of four different samples of the mud which include magnesium oxide (MgO) NPs and banana peel were used in this study. The results obtained as represented in a gel strength against time plot shows that sample 1 produced a progressive type gel which started flattened at $1 \mathrm{Ibf} / 100 \mathrm{ft} 2$ with $10 \mathrm{sec}$ and $10 \mathrm{~min}$ gel strength, but increased as static time increases. Sample 2 produced a flat-type gel which started of flat at $2 \mathrm{Ibf} / 100 \mathrm{ft} 2$ with the $10 \mathrm{sec}$ and 10min gel strength as same, but didn't progress steadily as the static time increases. Samples 3 produced a flat-type gel at $10 \mathrm{sec}$ and $10 \mathrm{~min}$; however, a high progressive type gel was obtained when the static time was increased. Also, samples 4 produced low flat-type gel as at $10 \mathrm{sec}$ and $10 \mathrm{~min}$ and at higher static time, it maintained a flat type gel when compared to other samples. The use of MgO NPs and banana peel affected the gel strength by increasing it to a desirable type of gelation that can prevent stuck pipe and formation damage which is associated with high circulation pressure needed to circulate the drilling mud.
\end{abstract}

Keywords: Banana Peel, Gel Strength, Mud, Magnesium Oxide Nanoparticles, Bentonite Clay, Local Additives

DOI: $10.7176 / \mathrm{JEES} / 11-10-08$

Publication date:October $31^{\text {st }} 2021$

\section{Introduction}

Drilling fluids are employed in oil and gas drilling operations, as well as geothermal wells, to provide a number of functions such as removing drilled cuttings, lubricating and cooling of the drill bit and proving hydrostatic pressure to maintain borehole stability. The fulfillment of these duties depends upon the type of lithology being drilled and numerous properties of the drilling fluid, which should be adjusted to achieve desired performance. Different substances have been added to water base drilling fluids to improve their performance. Natural polymers, such as xanthan gum are one of these materials used to establish the desired rheological filtration properties and to mitigate wellbore instability problems. Many natural polymers have been used as rheology modifiers (Kok and Alikaya 2005), wellbore stabilizers (Estes 1986), fluid loss reducers and drilling fluid invasion controllers (Sun et al. 2014). With the increase in well depth and higher bottom-hole temperature, the thermal stability of these polymers becomes a significant concern (Al-Yasiri 2019), and drilling fluid operations face significant technical and economic challenges. Dispersing nanoparticles (NPs) into drilling fluid has been recently proposed as a potential solution to improve the drilling fluid performance, especially under down-hole conditions (Alyasiri et al. 2017; Singh et al. 2010; Barry et al. 2015). Quite recently, considerable attention has been given to the study of NPs to improve drilling fluid performance (Al-Yasiri 2019). Srivatsa and Ziaja (2012) investigated the use of NPs to control mud filtrate volume in drilling fluids, while Javeri et al. (2011) looked at minimizing differential pipe sticking by using NPs to reduce the volume of fluid loss and mud cake thickness formation. William et al. 2014 and Hassani et al. (2016) developed thermal, electrical and high pressure high temperature (HPHT) rheology of water base mud (WBM) by applying NPs, by increasing the concentration of NPs promotes thermal and electrical features of drilling fluids and this enhanced thermal and electrical characteristics by approximately $35 \%$ when compared to normal WBM. On the other hand, a few studies revealed that certain NPs could improve the performance of polymer-based drilling fluids by strengthening their rheological, filtration and lubrication properties (Abdo et al. 2014; Alizadeh et al. 2015; Mao et al. 2015). 
Gel strength is the shear stress of drilling fluid that is measured at low shear rate after the drilling fluid is static for a certain period of time. The gel strength is one of the most important drilling fluid properties because it demonstrates the ability of the mud to suspend solid and weighting materials when at static condition. Most drilling fluids are thixotropic in nature, meaning it is time dependent, while the mud remain static or un-agitated especially during connections and operational down time, it begins to gel. Drilling fluids must be effective in moving cuttings from source locations through the mud system under dynamic conditions and an appropriate suspension of these cuttings under static conditions is desired. The high gel strengths developed by thixotropic muds after prolonged periods of rest create another problem for the drilling engineer, because the long-term gel strength is a major factor in the pressure required to break circulation after a round trip, and in the magnitude of swab and surge pressures (Ryen and HCH 2017). The constituent of the drilling fluid affect the behaviour of muds in terms of gel strength and time, the relation between gel strength and time varies widely from mud to mud, depending on composition, degree of flocculation, and little work has been done to establishing means of predicting long-term gel strengths of muds. Breaking circulation is a good test of gel strength and inertial forces in the drilling fluid. Good field practices require a slow start and gradual build-up of the pump rate while picking up the drill pipe; having the appropriate gel strength is desired in drilling operations so as to avoid other formation challenges.

Nanoparticles influence the performance of muds due to their high surface areas and interactive ability with other materials in the immediate environment, and consequently, impact on the abilities of the different rheological properties. Chemicals added to drilling fluids are meant to improve the performance of that mud in certain subsurface conditions. However, limitations still exist during the use of these traditional drilling fluids in spite of the chemicals added to improve the drilling fluid performance. The main limitations of water based drilling fluids are: the ability of WBM to dissolve salts which may lead to unwanted distortions in the density of the drilling mud (Al-Sallami and Al-Yasiri 2015). Moreover, the WBM is capable of interfering with the flow of gas and oil through porous media. Other limitations are the ability of WBM to promote the disintegration and dispersion of clays and the inability of WBM to drill through water sensitive shale, as well as the ability of WBM to corrode iron such as drill pipes, drill collars and drill bits (Mellot 2008). Research work done by Nabhani and Emami (2012) shows that wellbore instability problems arises when WBM are exposure to shale formations, because the mud losses more of its water content to shale materials. The drilling fluids that contain nanoparticles have the power to depreciate wellbore instability (Singh et al. 2010). Ragab and Noah (2014) affirmed that nanotechnology offers light, strong and corrosion-resistant materials which help the drilling fluids in adjusting the rheology by modifying the composition, type, or size distribution of nanoparticles in drilling fluid to accommodate any special situation. Nanomaterials are stronger and more reactive than other materials and they also conduct heat efficiently (Singh et al. 2010). The reason behind that is the increased surface interaction. As for given quantities of material, there are a higher number of particles as a result of their size reduction as well as there is more surface area to bear the heat (Shah et al. 2010).

This study focuses on the effects of magnesium oxides (MgO) NPs on the gel strength of water base mud WBM and the effects when banana peel is added to nano base mud. This compound is made up of magnesium and oxygen with a composition of $60.29 \%$ magnesium, while oxygen is $39.67 \%$. Its coating ability comprising of $\mathrm{MgCO}_{3} \bullet \mathrm{Mg}(\mathrm{OH})_{2}$, gives a good property that encourages high performance in the fixation of migrating fines (Fernandez-Garcia and Rodriguez 2007). Furthermore, the nano ability makes it viable in the attraction of negatively charged fines particles found in the formation. It has a very high surface energy due to its high surface area, and high porosity quality. This surface area gives it the ability to spread over the grain surface effectively and leads to the retaining of more migrating fines particles in porous media. The ability of the MgO NPs to attract negatively charged particles and influencing of its immediate environment informed its investigation on the effect on the gel gel strength of drilling fluid. Another important material in this study is the banana peels, and these peels are the major waste product of an herbaceous plant of the family of musacede known as musa sapientum which contribute to the existing environmental problems. The musa sapientum grows up to a height of about $2-8 \mathrm{~m}$ with leaves of about $3.5 \mathrm{~m}$ in length and the stem which is also called pseudostem produces a single bunch of banana before dying and replaced by new pseudostem (Anhwange et al. 2009). The fruit grows in hanging cluster of about twenty fruits or more to a tier and $3-20$ tiers to a bunch. The fruit is protected by its peel which is discarded as waste after the inner fleshy portion is eaten and this leads to a high quantity of waste to the environment. However, the problem can be recovered by adding value to its peels through its utilization in drilling mud beneficiation. The use of MgO NPs and banana peel combination in drilling mud will help not only in finding another alternative in improving on the gel strength of drilling mud but in eliminating banana peels waste from our environment. 


\section{Materials and Methods}

Experiments were carried out in the laboratory to achieve this investigation of the MgO NPs and banana peels when added to WBM. Bentonite clay (foreign clay), magnesium oxides (MgO) NPs, banana peels (local additive) and water were the main materials used in this research. Bentonite clay are formed by the alteration of minute glass particles derived from volcanic ash, and its formation involves the alteration of volcanic glass to clay minerals; this requires hydration a process that use up water and a loss of alkalis, bases and possibly silica, with the preservation of the textures of the original volcanic glass. Bentonite consists chiefly of crystalline clay minerals belonging to the smectite family of clay classification. This particular clay classification is hydrous aluminium silicates containing iron and magnesium as well as either sodium or calcium. It's of importance to note that two categories of bentonite are recognized and the uses of each depend on the specific physical properties

\subsection{Samples Preparation Procedures}

Four different samples were prepared and applied in the different experiments carried out during this laboratory study. Sample A is water base mud prepared from bentonite clay (foreign clay) without any other additives or NPs, it is a fresh mud used as the reference drilling fluid to ascertain the performance of other mud samples containing nano-materials or banana peels. Sample B is a combination of the WBM from bentonite clay and magnesium oxides $(\mathrm{MgO}) \mathrm{NPs}$, while sample $\mathrm{C}$ is WBM from bentonite clay and local additive of banana peel and sample D is a mixture of WBM also from bentonite clay with magnesium oxides $(\mathrm{MgO})$ and banana peel.

Sample A: This is a sample of fresh mud, sample preparation involves three different $350 \mathrm{ml}$ of water measured with a measuring cylinder. Also, $22 \mathrm{~g}$ of bentonite clay were measured in three different places with a weigh balance. $350 \mathrm{ml}$ of the water was poured into the mixer, with mixer switched on; $22 \mathrm{~g}$ of bentonite clay was added gradually to get an even mixture of the water and bentonite, and the mixer was allowed to stir for 10 minutes. The remaining two other measured $22 \mathrm{~g}$ of bentonite clay and $350 \mathrm{ml}$ of water were also stirred for 10 minutes in different containers. Each of the mixed water and clay were poured respectively into the mixing cups of the rheometer to a level of the scribe line of the cup and stirred for 15 seconds at $600 \mathrm{rpm}$. Then, the rpm (rev per minute) knob was turned to the stop position and allowed to obtain static time of $10 \mathrm{sec}$, 5mins. $10 \mathrm{mins}, 15 \mathrm{mins}, 20 \mathrm{mins}, 25 \mathrm{mins}$, $30 \mathrm{mins}, 35 \mathrm{mins}$ and $40 \mathrm{mins}$. The rpm knob was switched to gel position at $3 \mathrm{rpm}$ and then readings were recorded for each of the set out time at the maximum deflection of the dial before the gel breaks.

Sample B: As stated earlier, sample B is a mixture of fresh WBM and magnesium oxides MgO NPs. In preparing this sample, three different $350 \mathrm{ml}$ of water were measured with a measuring cylinder. Also, $22 \mathrm{~g}$ of bentonite clay were measured in three different places with a weigh balance, while three different quantities of magnesium oxides NPs of $0.5 \mathrm{~g}, 1.0 \mathrm{~g}$ and $2.0 \mathrm{~g}$ concentrations were measured using a weigh balance. $350 \mathrm{ml}$ of the water was poured into the mixer, with mixer switched on; $22 \mathrm{~g}$ of bentonite clay and $0.5 \mathrm{~g}$ of MgO NPs were added gradually to get an even mixture and stirring lasted for 10 minutes. The other two measured $1.0 \mathrm{~g}$ and $2.0 \mathrm{~g}$ of $\mathrm{MgO}$ NPs were also mixed with $22 \mathrm{~g}$ of bentonite clay and $350 \mathrm{ml}$ of water, stirred for 10 minutes in separate containers. The rpm knob was turned to the stop position and allowed to obtain static time of $10 \mathrm{sec}, 5 \mathrm{mins}$. $10 \mathrm{mins}, 15 \mathrm{mins}, 20 \mathrm{mins}, 25 \mathrm{mins}$, $30 \mathrm{mins}, 35 \mathrm{mins}$ and $40 \mathrm{mins}$. The rpm knob was switched to gel position at 3rpm and then readings were recorded for each of the set out time at the maximum deflection of the dial before the gel breaks.

Sample C: It contains a combination of fresh WBM and local additive of banana peel. Similarly, three different $350 \mathrm{ml}$ of water were measured with a measuring cylinder and three $22 \mathrm{~g}$ of bentonite clay were also measured using a weigh balance, while three $2.0 \mathrm{~g}$ of dry grounded banana peel was measured with weigh balance. $350 \mathrm{ml}$ of the water was poured into the mixer to commence mixing; $22 \mathrm{~g}$ of bentonite clay and $2.0 \mathrm{~g}$ of the dried grounded banana peel were added gradually to get an even mixture and stirring lasted for 10 minutes. The other two measured $2.0 \mathrm{~g}$ of the banana peels were also mixed with $22 \mathrm{~g}$ of bentonite clay and $350 \mathrm{ml}$ of water, stirring for 10 minutes in separate containers were aimed at getting proper mixing. The rpm knob was turned to the stop position and allowed to obtain static time of $10 \mathrm{sec}, 5 \mathrm{mins}$. $10 \mathrm{mins}, 15 \mathrm{mins}, 20 \mathrm{mins}, 25 \mathrm{mins}, 30 \mathrm{mins}, 35 \mathrm{mins}$ and $40 \mathrm{mins}$. The rpm knob was switched to gel position at $3 \mathrm{rpm}$ and then readings were recorded for each of the set out time at the maximum deflection of the dial before the gel breaks.

Sample D: The substances that made up sample D include fresh WBM from bentonite clay, magnesium oxides $(\mathrm{MgO}) \mathrm{NPs}$ and dry grounded banana peel. Sample D was prepared by measuring three different $350 \mathrm{ml}$ of water with a measuring cylinder and three $22 \mathrm{~g}$ of bentonite clay were measured with a weigh balance. Three different quantities of magnesium oxides NPs of $0.5 \mathrm{~g}, 1.0 \mathrm{~g}$ and $2.0 \mathrm{~g}$ concentrations as well as three dry grounded banana peels of $2.0 \mathrm{~g}$ each were also measured using a weigh balance. $350 \mathrm{ml}$ of the water was poured into the mixer, with mixer switched on; $22 \mathrm{~g}$ of bentonite clay, $2.0 \mathrm{~g}$ of dry grounded banana peel and $0.5 \mathrm{~g}$ of $\mathrm{MgO} \mathrm{NPs}$ were added gradually to get an even mixture and stirring lasted for 10 minutes. The other two measured $2.0 \mathrm{~g}$ of dry grounded 
banana peel with $1.0 \mathrm{~g}$ and $2.0 \mathrm{~g}$ of $\mathrm{MgO}$ NPs were also mixed with $22 \mathrm{~g}$ of bentonite clay and $350 \mathrm{ml}$ of water in separate containers and allowed to stir for 10 minutes. The rpm knob was turned to the stop position and allowed to obtain static time of $10 \mathrm{sec}, 5 \mathrm{mins} .10 \mathrm{mins}, 15 \mathrm{mins}, 20 \mathrm{mins}, 25 \mathrm{mins}, 30 \mathrm{mins}, 35 \mathrm{mins}$ and $40 \mathrm{mins}$. The rpm knob was switched to gel position at 3rpm and then readings were recorded for each of the set out time at the maximum deflection of the dial before the gel breaks.

Banana Peels Preparation: The banana peels were locally sourced, prepared and added as local additive. The banana peels were sourced from local vendors, with a keen focus on the particular kind of banana peel obtained in forest region of the Niger Delta. The banana peel powder was prepared utilizing dry milling method (DMM) which involves sun drying the banana peels for few days and using a grounding machine to convert the dried banana peels to its powder form so as to ease its mixture with the WBM and the MgO NPs. This powered form contains protein, fats, starch and ash (Wachirasiri et al. 2009).

\section{Results and Analysis}

The results presented in table 1 are the results obtained from the four different samples adopted in this research. The addition of MgO NPs to the prepared drilling mud resulted in increase of the gel strength at different proportions. It can also be seen that this increase in gel strength is directly proportional to the concentration of the $\mathrm{MgO}$ NPs added to the fresh mud, as the concentration increased from $0.5 \mathrm{~g}$ to $1.0 \mathrm{~g}$ of $\mathrm{MgO} \mathrm{NPs}$ which was added to the drilling mud, the gel strength increased as well, similar increase were also recorded when it increased from $1.0 \mathrm{~g}$ to $2.0 \mathrm{~g}$ of $\mathrm{MgO} \mathrm{NPs}$. The local additive (banana peel) added also behaved in similar manner, however, the concentration of banana peel was kept constant through the laboratory investigation, because more work is still on going at this stage which will be reported at the appropriate time. The results obtained from the sample $\mathrm{C}$ which has only banana peel as additive showed better performance in affecting the gel strength of the drilling mud; this may be attributed to the high percentage of starch and ash as well as the presence of fats and proteins in the banana peels (Wachirasiri et al. 2009). These dried powered form banana peel added some absorbing ability to the drilling mud by helping to hold the water content of the mud and the other materials present together. These banana peels improved on the gel strength of the mud which is one of the most important drilling fluid properties because it demonstrate the ability of the drilling fluid to suspend solid and weighting materials when circulation is ceased. In figures 1 to 8 the effects of the nano material and the banana peel are seen on the patterns of the gel strength formed. These patterns of gel strength generated from this study followed existing types of gel strength in literatures, suggesting that the materials used as additive or beneficiation of the drilling fluid have the needed potential to be applied in subsurface or reservoir conditions. Depending on the time it takes to gel, we have three types of gel strength namely; the high flat gel, progressive gel and the low flat gel (which are mostly desirable). Depending on the range between $10 \mathrm{sec}$ and $10 \mathrm{mins}$ gel reading, the range difference is significantly high for both the high and progressive gel, and it indicates rheological challenges for drilling mud. However, there is no real difference for that of low flat gel, for the magnitude of gelation with time is a key factor in mud and it should not be too high to suspend cuttings and weighed materials.

Table 1.0: Gel Strength Obtained from Fresh Mud and MgO NPs with Local Additive

\begin{tabular}{|c|c|c|c|c|c|c|c|c|}
\hline \multirow[b]{3}{*}{$\begin{array}{c}\text { Time } \\
\text { (mins) }\end{array}$} & \multicolumn{8}{|c|}{ Gel Strength $\left(\mathrm{Ibf} / \mathbf{1 0 0 \mathrm { ft } ^ { 2 } )}\right.$} \\
\hline & \multirow{2}{*}{$\begin{array}{l}\text { Sample A } \\
\text { Blank Mud }\end{array}$} & \multicolumn{3}{|c|}{$\begin{array}{r}\text { Sample B } \\
\end{array}$} & Sample C & \multicolumn{3}{|c|}{ Sample D } \\
\hline & & $\begin{array}{l}\text { Mud + } \\
\text { 0.5g } \\
\text { MgO } \\
\text { NPs }\end{array}$ & $\begin{array}{l}\text { Mud + } \\
1.0 g \\
\text { MgO } \\
\text { NPs }\end{array}$ & $\begin{array}{l}\text { Mud + } \\
2.0 g \\
\text { MgO } \\
\text { NPs }\end{array}$ & $\begin{array}{l}\text { Mud + } \\
2.0 \mathrm{~g} \\
\text { Banana } \\
\text { Peel }\end{array}$ & $\begin{array}{l}\text { Mud + } \\
\text { 0.5g MgO } \\
\text { NPs }+2.0 g \\
\text { Banana } \\
\text { Peel }\end{array}$ & $\begin{array}{lr}\text { Mud + } \\
\text { 1.0g MgO } \\
\text { NPs + } \\
2.0 g \\
\text { Banana } \\
\text { Peel }\end{array}$ & $\begin{array}{l}\text { Mud }+2.0 g \\
\text { MgO NPs }+ \\
\text { 2.0g Banana } \\
\text { Peel }\end{array}$ \\
\hline $10 \mathrm{sec}$ & 1 & 2 & 3 & 5 & 3 & 10 & 12 & 12 \\
\hline 5 & 1 & 2 & 4 & 6 & 14 & 12 & 14 & 14 \\
\hline 10 & 1 & 3 & 5 & 7 & 16 & 12 & 14 & 15 \\
\hline 15 & 2 & 3 & 6 & 8 & 18 & 14 & 16 & 17 \\
\hline 20 & 3 & 4 & 6 & 10 & 20 & 15 & 17 & 18 \\
\hline 25 & 4 & 4 & 7 & 10 & 22 & 16 & 18 & 19 \\
\hline 30 & 5 & 5 & 8 & 11 & 24 & 17 & 18 & 20 \\
\hline 35 & 6 & 6 & 9 & 12 & 26 & 18 & 19 & 21 \\
\hline 40 & 7 & 6 & 10 & 14 & 28 & 18 & 20 & 22 \\
\hline
\end{tabular}


The results presented in figure 1 is indicating a progressive gel which started of flat at $11 \mathrm{lbf} / 100 \mathrm{ft}^{2}$ with the $10 \mathrm{sec}$ and $10 \mathrm{mins}$ showing same results, however, the gel strength progress steadily as the static time increases. This type of gelation is undesirable in the drilling mud used in drilling a well, most of the drilled wellbore are product of drilling muds that have been fortified with weighting materials or additives and so many of these materials have been tested and applied. For this study, fresh drilling muds that contained no weighting materials or other additives were prepared and this is obvious in the progressive nature of the gel strength. A close look at figures 2 to 8 showed a deviation from the progressive gel in figure 1 to low flat gels that are mostly desirable in a drilling mud. The desirable changes were as a result of the addition of MgO NPs to the drilling mud, the flat gelation was noticed more as the concentration of the NPs increased. The results obtained when banana peel was added to MgO NPs indicated a more low flat gel on the drilling mud, suggesting that the electrostatic force that exist at that moment between that MgO NPs and the banana peel created an attractive force between these substances (constituents of the mud, banana peel constituents and MgO NPs) which resulted in the gelation change and low flat gel.

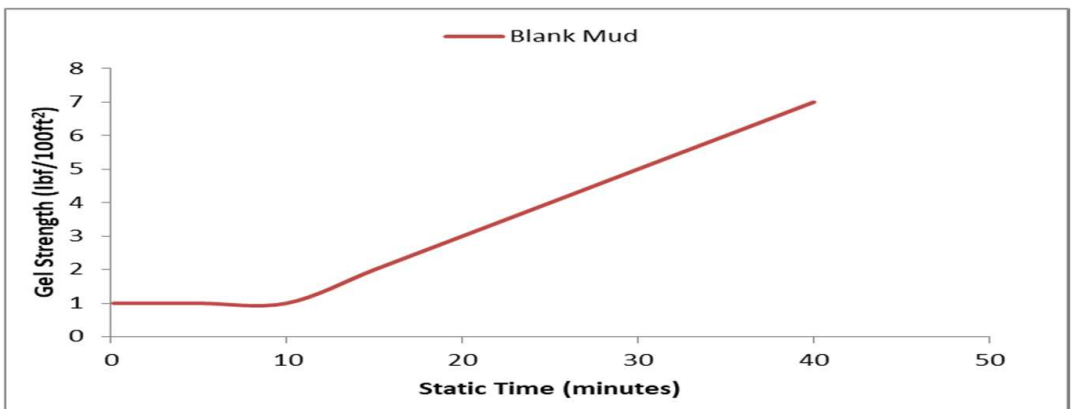

Figure 1: Gel Strength of a Bentonite Clay Mud without Additives

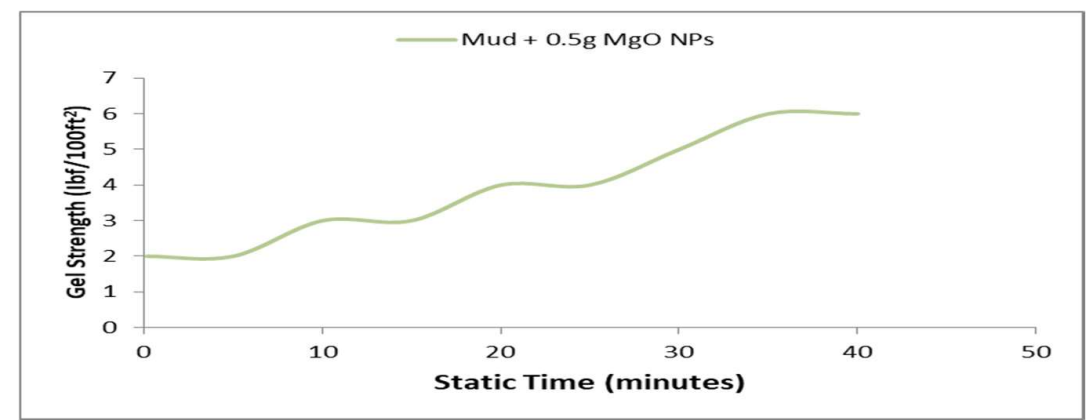

Figure 2: Gel Strength of a Bentonite Clay Mud with 0.5g MgO NPs

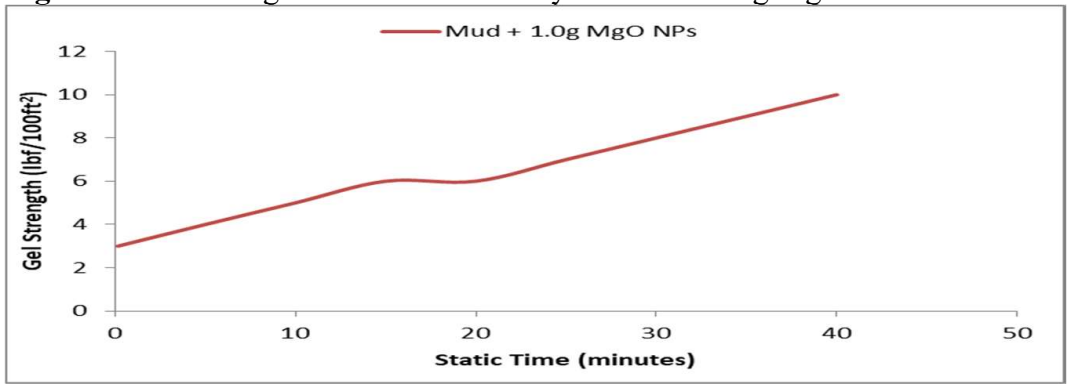

Figure 3: Gel Strength of a Bentonite Clay Mud with 1.0g MgO NPs 


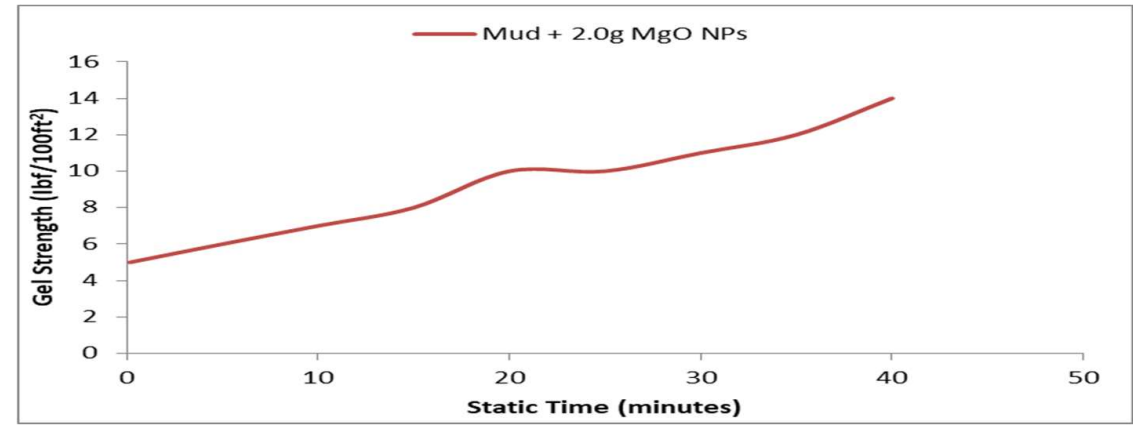

Figure 4: Gel Strength of a Bentonite Clay Mud with 2.0g MgO NPs

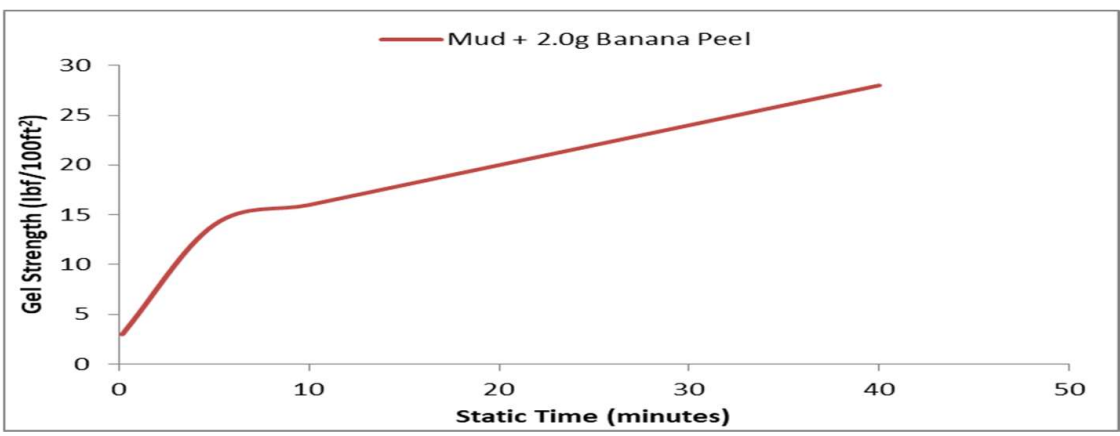

Figure 5: Gel Strength of a Bentonite Clay Mud with 2.0g Banana Peel

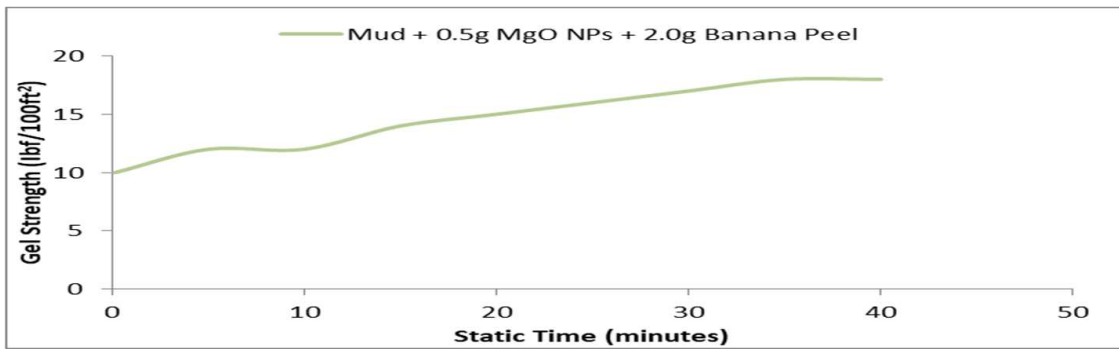

Figure 6: Gel Strength of a Bentonite Clay Mud with 0.5g MgO NPs and 2.0g Banana Peel

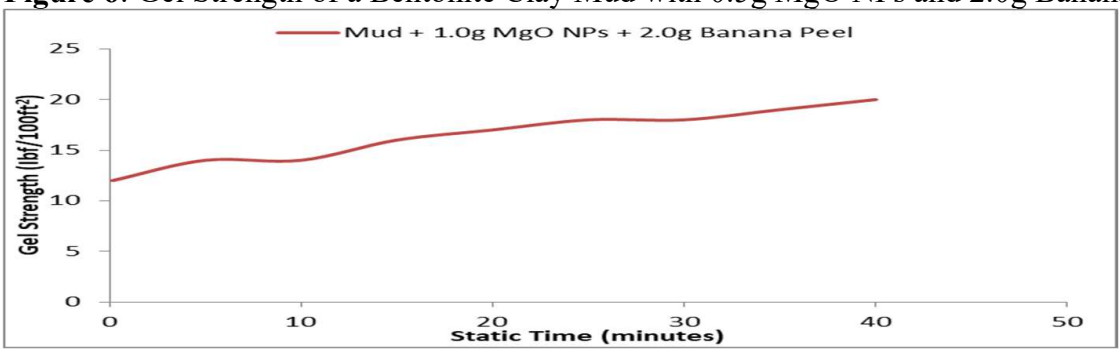

Figure 7: Gel Strength of a Bentonite Clay Mud with 1.0g MgO NPs and 2.0g Banana Peel

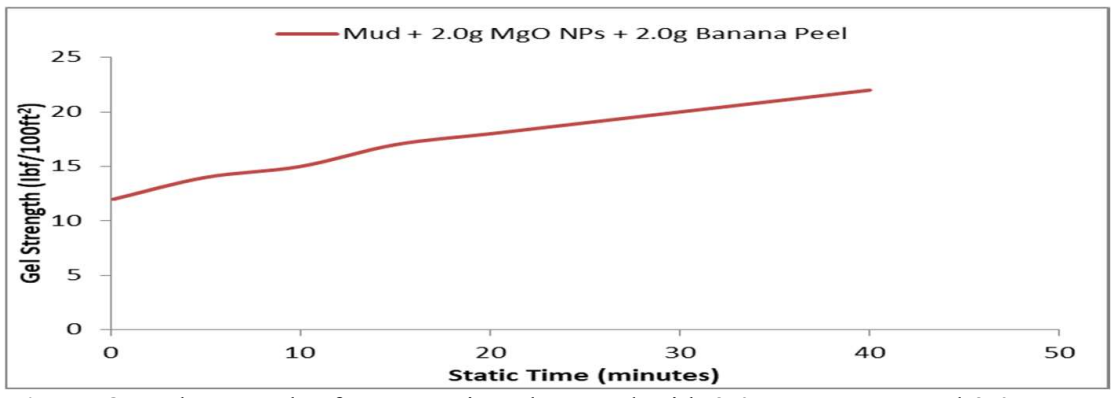

Figure 8: Gel Strength of a Bentonite Clay Mud with 2.0g MgO NPs and 2.0g Banana Peel 
As seen in figure 2 , the bentonite clay WBM having a $0.5 \mathrm{~g} \mathrm{MgO}$ NPs produced a flat-type gel, this started flat at $2 \mathrm{lbf} / 100 \mathrm{ft}^{2}$ with the $10 \mathrm{sec}$ and $10 \mathrm{mins}$ gel strength as the same but did not progress steadily as the static time increases. Other sample of the prepared drilling mud with the banana peel as presented in figure 5 showed a progressive gel that has the tendency to increase more as static time increases. Figure 9 is the comparison of the performance of the different samples prepared for this investigation, it can be seen that these substances affect the gel strength by increasing it. The API standard of measuring gel strength is to allow a static condition to exist for $10 \mathrm{sec}$ and $10 \mathrm{~min}$ after the mud has been $300 \mathrm{rpm}$ or $600 \mathrm{rpm}$, the corresponding readings gives the true type of gel. Figure 10 shows the effect of the mud samples prepared from MgO NPs and banana peel on gel strength at different concentrations at 10 second and 10 minutes respectively. Both MgO NPs and banana peel shows an increasing trend as concentration increased and this phenomenon occurs due to the link between banana peel and the $\mathrm{MgO}$ NPs with water base mud within $10 \mathrm{sec}$ and $10 \mathrm{~min}$, resulting in a rigid structure and consequently, increasing the gelling effect. At the point of reduce gel strength, repulsive effects of these compositions sufficed.

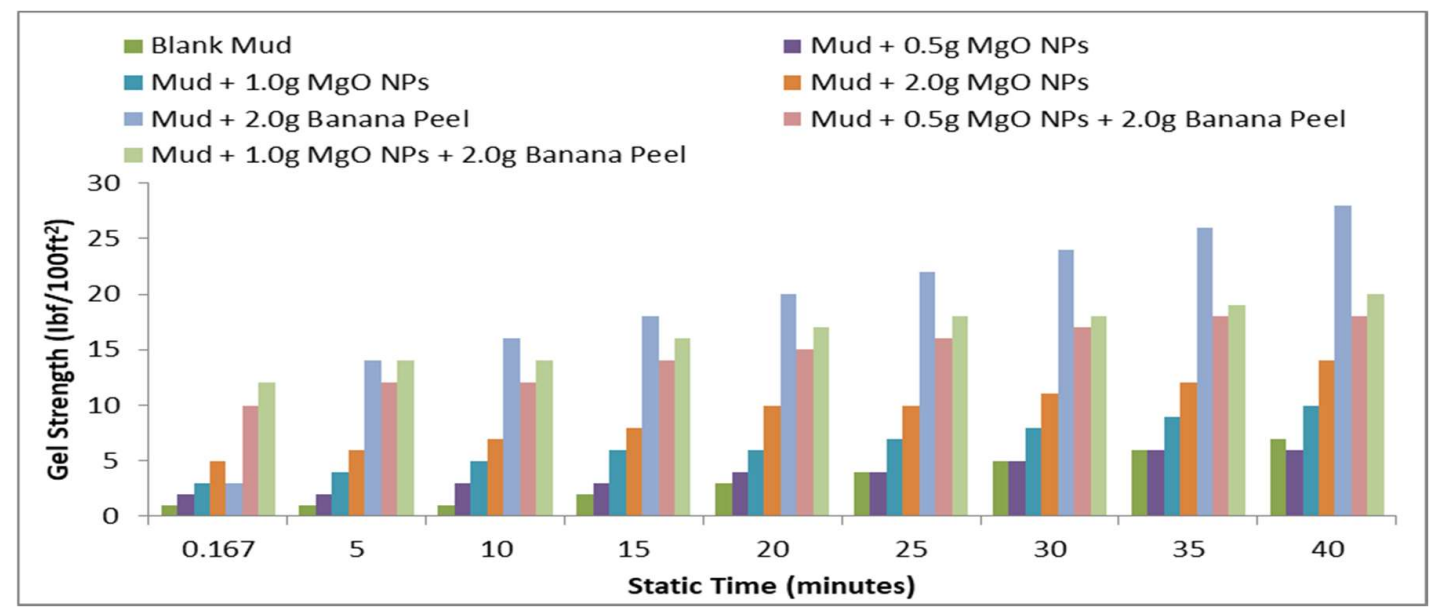

Figure 9: The Performance of Banana Peel and Different Concentration of MgO NPs on the Gel Strength of Drilling Fluid

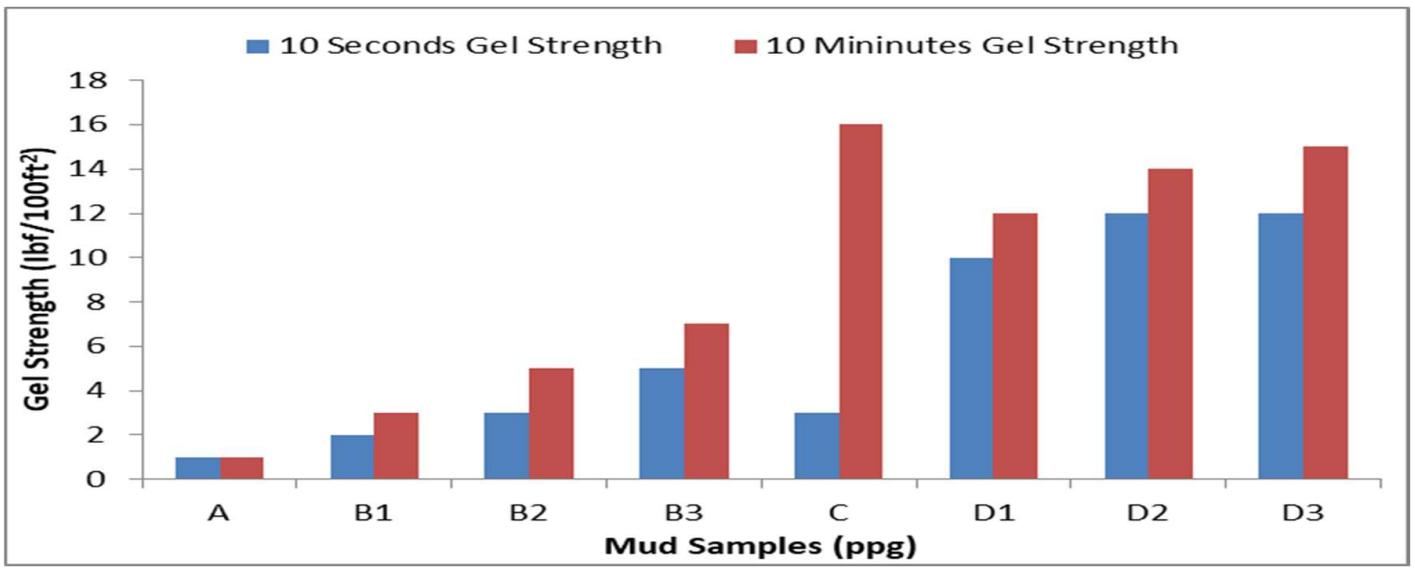

Figure 10: The Effect of MgO NPs and Banana Peel on Gel-Strength (10 sec \& 10 mins)

\section{Samples Constituents}

The following were the constituents of the different samples prepared for this research as presented in figure 10;

Fresh Mud

Fresh Mud + 0.5g MgO NPs

Fresh Mud + 1.0g MgO NPs

Fresh Mud + 2.0g MgO NPs

Fresh Mud + 2.0g Banana Peel

Fresh Mud+0.5g MgO NPs+2.0g Banana Peel

Fresh Mud+1.0g MgO NPs+2.0g Banana Peel

Fresh Mud+2.0g MgO NPs+2.0g Banana Peel
A

B1

B2

B3

- D2

- D3 
The study of magnesium oxide nanoparticle and banana peel on the gel strength of water base drilling mud has answered some questions as regard the extent of these additional materials on already established WBM. The data and analysis earlier stated revealed how magnesium oxides nanoparticles (MgO NPs) and banana peel can change the gel strength of a fresh bentonite clay mud from a certain gel type to another and what happens if there is increase in the static time of the drilling mud. In achieving the aim of this research, certain standards of laboratory procedures for preparing mud samples were attained and sustained, which resulted in data earlier presented. However, some other questions and observations have arisen in trying to generate solutions to keen area of the drilling operations. Further study will always be appropriate to finding more solutions to the challenges of the oil and gas industry and drilling operations in particular.

\section{Conclusion}

The use of magnesium oxides nanoparticles and banana peel in finding adequate solutions to getting the desired gelation of water base drilling mud has been established in this work. Except magnesium oxides nanoparticles which is largely produced outside the shores of Niger delta, banana peels of industrial quantities can be sourced locally from vendors. This gives it more advantage for industrial applications of these materials either in further research or implementation of findings discovered in this study. The determination of the effect of MgO NPs and banana peel on the gel strength of WBM has been achieved successfully with the results presented, based on this, the following conclusions were drawn;

1) Magnesium oxides nanoparticles and banana peel affect the gel strength of fresh bentonite clay water base mud by altering the gel type to a more desirable gel.

2) The use of banana peel only in altering the gel strength of a bentonite clay water base mud is effective, however, undesirable because it result in progressive gel type.

3) The gelation type obtained is dependent on the concentration of magnesium oxides nanoparticles added to the bentonite clay water base mud because low concentration of $0.5 \mathrm{~g} \mathrm{MgO} \mathrm{NPs}$ only and other concentrations of $\mathrm{MgO}$ NPs combined with banana peel favours the desirable low flat gel type.

\section{Acknowledgement}

The authors of this work acknowledge the immense contribution of Silver Damigoru of the Department of Petroleum Engineering, Faculty of Engineering, University of Benin, Benin City during the research stages of this work.

\section{References}

Abdo, J., Zaier, R. Hassan, E., Al-Sharji, H. and Al-Shabibi, A. (2014):, "ZnO-Clay Nanocomposites for Enhance Drilling at HTHP Conditions". John Wiley and Sons Ltd., ECASIA Special Paper, Surface and Interface Analysis 46(10 - 11) doi 10.1002/sia5454 www.wileyonlinelibrary.com

Alizadeh, S., Sabbaghi, S. and Soleymani, M. (2015):, "Synthesis of Alumina/Polyacrylamide Nanocomposite and Its Influence on Viscosity of Drilling Fluid”. International Journal of Nano Dimension, 6(3), pp. 271 - 276, www.ijnd.ir

Anhwange, B. A., Ugye, T. J. and Nyiaatagher, T. D., (2009):, “Chemical Composition of Musa Sapientum (Banana) Peels". Electronic Journal of Environmental, Agricultural and Food Chemistry. 8(6) pp. 437 - 442. https://www.researchgate.net/publication/233760453

Al-Sallami, W. T. and Al-Yasiri, M. (2015):, "How the Drilling Fluids can be Made More Efficient By Using Nanomaterials". American Journal of Nano Research and Applications 3(3) pp. $41 \quad-45$ https://doi.org/10.11648/j:nano.20150303.12

Al-Yasiri, M. S. (2019):, "Improving the Performance of Drilling Fluids by Using Nanoparticles". PhD Thesis, University of Leeds

Alyasiri, M., Anthony, J. and Wen, D. (2017):, "Enhancement of Drilling Fluid Rheology by Nanoparticles". Annual Transactions of the Nordic Rheology Society, Vol. 25, pp. 349 - 351

Barry, M. M., Jung, Y., Lee, J. K., Phuoc, T. X. and Chyu, M. K. (2015):, "Fluid Filtration and Rheological Properties of Nanoparticles Additive and Intercalated Clay Hybrid Bentonite Drilling Fluids". Journal Petrol 
Sci. Eng. 127 pp. 338 - 346 https://doi.org/10.1016/j.petrol.2015.01.012

Estes, J. C. (1986):, "Role of Water Soluble Polymers in Oil Well Drilling Muds". American Chemical Society Publications; Advances in Chemistry, Vol. 213, Chapter 9, pp. 155 - 170 doi:10.1021/ba-1986-0213.ch009

Fernandez-Garcia, M. and Rodriguez, J. A. (2007):, "Metal Oxide Nanoparticles". A Book Published in Nanomaterials: Inorganic and Bioinorganic Perspectives, Chemistry Department, Brookhaven National Laboratory P.O. Box 5000, Upton, NY 11973-5000 www.bni.gov

Hassani, S. S., Amrollahi, A., Rashidi, A. Soleymani, M. and Rayatdoost, S. (2016):, "The Effect of Nanoparticles on the Heat Transfer Properties of Drilling Fluids”. J. Pet. Sci. Eng., 146, pp. $183-90$

Javeri, S. M., Haindade, Z. M. W. and Jere, C. B. (2011):, "Mitigating Loss Circulation and Differential Sticking Problems Using Silicon Nanoparticles". SPE/IADC Paper No. SPE-154840-MS presented to Middle East Drilling Technology Conference and Exhibition https:/doi.org/10.2118/145840-MS

Kok, M. V. and Alikaya, J. (2005):, "Effect of Polymers on the Rheological Properties of KCL/Polymer Type Drilling Fluids". Energy Sources Vol. 27, 1ssue 5, pp. $405 \quad-415$ https://doi.org/10.1080/00908310490441809

Mao, H., Qiu, Z., Shen, Z., Huang, W., Zhong, H. and W. Dai, W. (2015):, "Novel Hydrophobic Associated Polymer Based Nano-Silica Composite with Core-Shell Structure for Intelligent Drilling Fluid Under UltraHigh Temperature and Ultra-High Pressure”. Prog. Nat. Sci. Mater. Int. 25 (1), pp. 90 - 93, https://doi.org/10.1016/j.pnsc.2015.01.013.

Mellot, J. (2008):, “Technical Improvements in Wells Drilled with a Pneumatic Fluid”, SPE Paper 99162, Presented at SPE/IDAC Drilling Conference, Miami, Florida, USA, pp. 21-23

Nabhani, N. and Emami, M. (2012 ):, "The Potential Impact of Nanoparticles in Oil Drilling Industry”. Nanocon, International Conference on Nanomaterials-Research Applications 23-25 October, Brno, Czech Republic, EU.

Ragab, A. S. and Noah, A. (2014):, "Reduction of formation damage and fluid loss using nano-sized silica drilling fluids". Petroleum Technology Development Journal, 2, pp. 75 - 88

Ryen, C. and HCH, D. (2017):, "Composition and Properties of Drilling and Completion Fluids". 7th ed. Texas: Gulf Professional Publishing, p.13 (643).

Shah, S. N., Shanker, N. H. and Ogugbue, C. C. (2010):, "Future Challenges of Drilling Fluids and Their Rheological Measurements". In AADE Fluids Conference and Exhibition, Houston, Texas

Singh, S., Ahmed, R. and Growcock, F. (2010):, "Vital Role of Nanoparticles in Drilling and Stimulations Fluid Applications". Paper SPE 130413 Presented at the SPE Annual Technical Conference and Exhibition, Florence, Italy, pp. $19-22$

Srivatsa, J. T. and Ziaja, M. B. (2012):, “An Experimental Investigation on Use of Nanoparticles as Fluid Loss Additives in a Surfactant-Polymer Based Drilling Fluid". Presented at the International Technology Conference, Bangkok, Thailand, 7 - 9 February. IPTC-14952-MS.

Sun, Y., Teng, F. and Zhao, J. (2014):, "Study and application of Polymer-Film Forming Shielding Plugging Drilling Fluid System". Hindawi Publishing Corporation; Journal of Petroleum Engineering Vol. 2014, Article ID 824020, 5pages http://www.hindawi.com

Wachirasiri, P., Julakarangka, S. and Wanlapa, S. (2009):, "The Effects of Banana Peels Preparation on the Properties of Banana Peel Dietary Fibre Concentrate”. Songklanakarin Journal of Science and Technology, 31(6), pp. 605 - 611 https://www.sjst.psu.ac.th

William, J. K. M., Ponmani, S., Samuel, R., Nagarajan, R. and Sangwai, J. S. (2014):, “Effect of CuO and ZnO Nanofluids in Xanthan Gum on Thermal, Electrical and High Pressure Rheology of Water- Based Drilling Fluids”. J. Pet. Sci. Eng., 117, pp. $15-27$ 